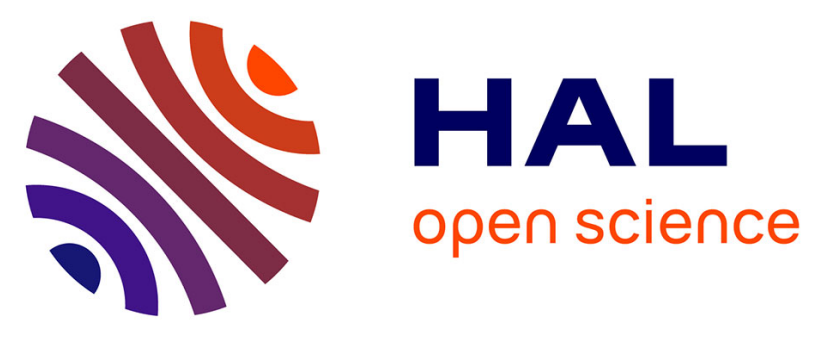

\title{
Influence of gate leakage current on AlGaN/GaN HEMTs evidenced by low frequency noise and pulsed electrical measurements
}

Serge Karboyan, Jean-Guy Tartarin, M Rzin, L Brunel, A Curutchet, N Malbert, N Labat, D Carisetti, B Lambert, M Mermoux, et al.

\section{To cite this version:}

Serge Karboyan, Jean-Guy Tartarin, M Rzin, L Brunel, A Curutchet, et al.. Influence of gate leakage current on AlGaN/GaN HEMTs evidenced by low frequency noise and pulsed electrical measurements. Microelectronics Reliability, 2013, European Symposium on Reliability of Electron Devices, Failure Physics and Analysis, 53 (9-11), pp.1491-1495. 10.1016/j.microrel.2013.07.020 . hal-01343328

\section{HAL Id: hal-01343328 \\ https://hal.science/hal-01343328}

Submitted on 12 Jul 2016

HAL is a multi-disciplinary open access archive for the deposit and dissemination of scientific research documents, whether they are published or not. The documents may come from teaching and research institutions in France or abroad, or from public or private research centers.
L'archive ouverte pluridisciplinaire HAL, est destinée au dépôt et à la diffusion de documents scientifiques de niveau recherche, publiés ou non, émanant des établissements d'enseignement et de recherche français ou étrangers, des laboratoires publics ou privés. 


\title{
Influence of gate leakage current on $\mathrm{AlGaN} / \mathrm{GaN}$ HEMTs evidenced by low frequency noise and pulsed electrical measurements
}

\author{
S. Karboyan ${ }^{\mathrm{a}, *}$, J.G. Tartarin ${ }^{\mathrm{a}}$, M. Rzin ${ }^{\mathrm{b}}$, L. Brunel ${ }^{\mathrm{b}, \mathrm{d}}$, A. Curutchet ${ }^{\mathrm{b}}$, \\ N. Malbert ${ }^{\mathrm{b}}$, N. Labat ${ }^{\mathrm{b}}$, D. Carisetti ${ }^{\mathrm{c}}$, B. Lambert ${ }^{\mathrm{d}}$, M. Mermoux ${ }^{\mathrm{e}}$,

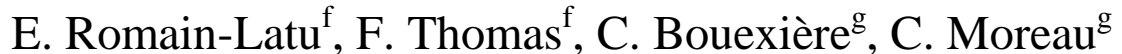 \\ ${ }^{a}$ LAAS-CNRS, University of Toulouse, 7 avenue du Colonel Roche, 31031 Toulouse, France \\ ${ }^{\mathrm{b}}$ IMS, CNRS UMR 5218, University of Bordeaux, 351 Cours de la Libération, 33405 Talence, France \\ ${ }^{\mathrm{c}}$ Thales Research and Technology, 1 avenue Augustin Fresnel, 91767 Palaiseau, France \\ ${ }^{d}$ United Monolithic Semiconductor, 10 avenue du Québec, 91140 Villebon sur Yvette, France \\ ${ }^{e}$ LEPMI, UMR 5279 CNRS, 1130 rue de la Piscine, 38402 Saint-Martin d'Heres, France \\ ${ }^{f}$ SERMA Technologies, 7 Parvis Louis Néel Minatec - BHT, 38040 Grenoble, France \\ ${ }^{g}$ Délégation Générale de l'Armement, La Roche Marguerite, 35998 Rennes, France
}

\begin{abstract}
The study of the pulsed drain current or noise characteristics in AlGaN/GaN HEMTs is the key of knowledge for designing the power amplifiers, the low noise amplifiers and the oscillators or mixers, but it is well accepted today that this study is not fully accomplished without pointing on the effect of the gate leakage current; It is obvious that the transistor's leakage current may disturb its operation at high power and high frequency. Leakage currents studies are also an area of great importance in optimization of safe operating area and reliability of HEMTs. Therefore, room temperature pulsed I-V and low frequency noise measurements of gate and drain currents of AlGaN/GaN HEMTs have been investigated under different bias conditions on two devices showing identical drain current and different gate current levels. The results show a correlation between two non-destructive measurement techniques applied on devices under test.
\end{abstract}

\section{Corresponding author.}

tartarin@laas.fr

Tel: +33 (5) 61337996 


\title{
Influence of gate leakage current on $\mathrm{AlGaN} / \mathrm{GaN}$ HEMTs evidenced by pulsed I-V and low frequency noise measurements
}

\author{
S. Karboyan ${ }^{\mathrm{a}, \text { * }}$, J.G. Tartarin ${ }^{\mathrm{a}}$, M. Rzin ${ }^{\mathrm{b}}$, L. Brunel ${ }^{\mathrm{b}, \mathrm{d}}$, A. Curutchet ${ }^{\mathrm{b}}$, \\ N. Malbert ${ }^{\mathrm{b}}$, N. Labat ${ }^{\mathrm{b}}$, D. Carisetti ${ }^{\mathrm{c}}$, B. Lambert ${ }^{\mathrm{d}}$, M. Mermoux ${ }^{\mathrm{e}}$,

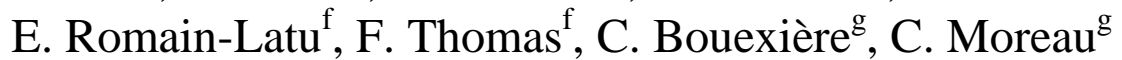

\section{Introduction}

AlGaN/GaN High Electron Mobility Transistors (HEMTs) are of great interest for microwave circuits (power amplifiers, robust low noise amplifiers, high frequency switches,...) because of their properties matched for high power, high frequency and low noise applications [1]. If the first reliability studies were focused on the drain current behavior in the channel, it is now largely assumed that leakage currents are major indicators of the state of a device, and are more prone to reveal their future degradation. The improvement of the reliability for a technology must be achieved through the close control of the leakage current. The gate control zone is then the sensitive area where the performances of the device can be optimized as it determines the drain current flowing in the channel during the life of the device. The present paper is not related to reliability purpose but focuses on electrical and noise analysis on the gate and drain terminals to evidence specific mechanisms induced on leaky and non-leaky devices. Thus, the qualification of these devices needs rigorous experiments on the drain as well as on the gate current.

The paper focuses on the electrical and low frequency noise characterization of devices issued from an industrial process:

(a) Pulsed I-V measurements are presented on the gate and drain currents. These measurements provide information about traps activated under non-isothermal conditions [2-4].

(b) Low frequency noise (LFN) measurements are performed on gate and drain terminals. This technique is convenient for getting fine information about the nature of the defects and their location in the device [5-7].
These techniques are performed on a set of devices featuring high and low leakage levels. Next, the results are proposed for one representative device from each set. This study highlights the impact of gate conduction mechanisms over the transistor behavior despite the quasi-similar drain current values measured for both transistors. Drain current is also investigated as defects can impact the dynamic characteristics of the device.

The paper is organized as follows. In section 2, we briefly describe the device structure and the experimental conditions used for the two techniques. Sections 3 and 4 report on the pulsed I-V and LFN measurements respectively. Section 5 sets the conclusions drawn from the two techniques.

\section{Devices under test and experimental conditions}

$\mathrm{AlGaN} / \mathrm{GaN}$ HEMTs under study $(4 \times 400 \mu \mathrm{mx} 0.5 \mu \mathrm{m})$ are grown on $\mathrm{SiC}$ substrate by MOCVD, and feature $18 \%$ of $\mathrm{Al}$ content. Two devices are tested presenting differences in the gate leakage current: T1 with low leakage current $(265 \mu \mathrm{A} / \mathrm{mm} @$ $\mathrm{V}_{\mathrm{DS}}=50 \mathrm{~V}$ and $\mathrm{V}_{\mathrm{GS}}=-7 \mathrm{~V}$ ) and $\mathrm{T} 2$ with high leakage current ( $855 \mu \mathrm{A} / \mathrm{mm}$, same biasing conditions). These devices are representative of each set of leaky and nonleaky devices, featuring a Gaussian distribution on the $\mathrm{I}_{\mathrm{GS}}$ values (at a given quiescent point $\mathrm{V}_{\mathrm{DS}}, \mathrm{V}_{\mathrm{GS}}$ ).

The pulsed I-V measurements are carried out at different quiescent bias $(\mathrm{QB})$ conditions $\left(\mathrm{V}_{\mathrm{GSO}}, \mathrm{V}_{\mathrm{DS} 0}\right)$ in order to quantify the gate and drain lag phenomena [2]:
(1) $\left(\mathrm{V}_{\mathrm{GS} 0}, \mathrm{~V}_{\mathrm{DS} 0}\right)=(0 \mathrm{~V}, 0 \mathrm{~V})$
(2) $\left(\mathrm{V}_{\mathrm{GSO}}, \mathrm{V}_{\mathrm{DS} 0}\right)=(-3 \mathrm{~V}, 0 \mathrm{~V})$,
(3) $\left(\mathrm{V}_{\mathrm{GS}}, \mathrm{V}_{\mathrm{DS} 0}\right)=(-3 \mathrm{~V}, 20 \mathrm{~V})$

To quantify the gate-lag effects, measurements carried out with conditions (1) and (2) are compared. 
The drain-lag effects are quantified by comparing measurements performed with conditions (2) and (3). A pulse width of $300 \mathrm{~ns}$ is used with a duty cycle of $0.01 \%$ to reduce self-heating effects.

LFN measurements are performed in a shielded room to reduce interferences with the external environment. Outside this room, the measurements are recorded on a computer connected to the HP89410A analyzer. A set of bias-Tees are used to prevent from possible oscillation of the devices. To set the bias point, gate and drain-biasing resistors are connected to batteries to reduce the excess noise sources which may be caused by a power supply. A Model 5182 transimpedance preamplifier (for the gate current LFN measurements) and a Model 5184 voltage preamplifier (for the drain current LFN measurements) are used to amplify the output signal level measured on the analyzer. The measurements are carried out at room temperature in the frequency range $1 \mathrm{~Hz}-100 \mathrm{kHz}$.

\section{Pulsed I-V measurements: Gate-lag and drain-lag effects}

\subsection{Gate lag effects}

The gate-lag (GL) is a delayed response of the drain current with respect to the gate voltage variation [8].

Figure 1 shows $300 \mathrm{~ns}$ pulsed I-V measurements of

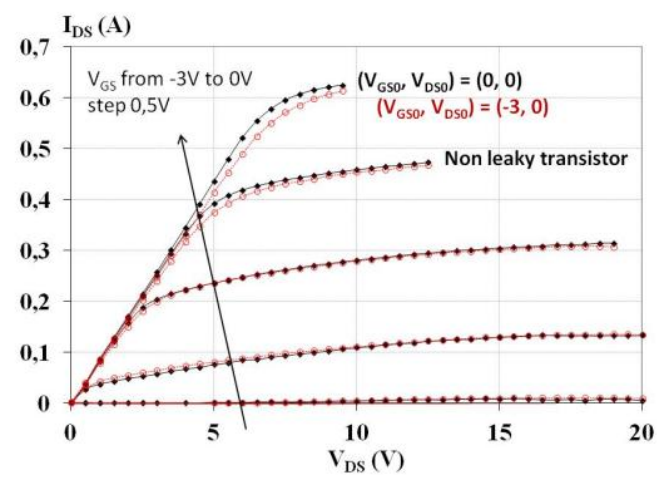

(a)

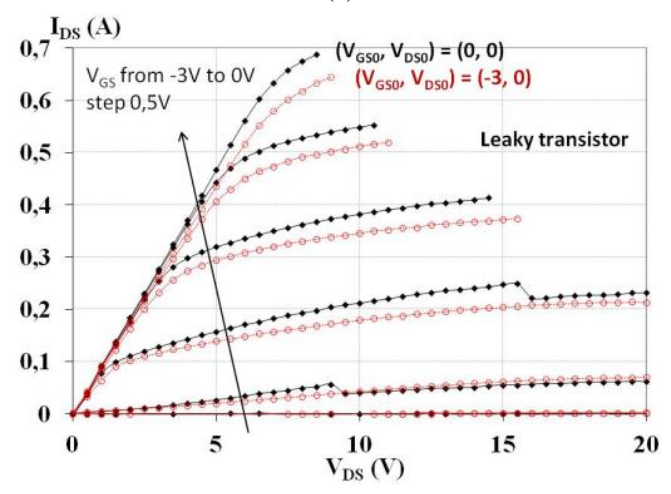

(b)

Fig. 1. 300ns pulsed I-V measurements of the $\mathrm{AlGaN} / \mathrm{GaN}$ HEMTs at QB conditions (1) and (2). (a) non-leaky transistor T1.(b) leaky transistor T2. a non-leaky and a leaky HEMTs (Figure 1a for T1 and Figure $1 \mathrm{~b}$ for $\mathrm{T} 2$ ) using the two quiescent bias conditions (1) and (2): from Figure 2, it is obvious that the non-leaky HEMT presents a gate lag ratio lower than $5 \%$ in all the $\mathrm{V}_{\mathrm{DS}}$ range and that the gate lag is more pronounced for the leaky device over the same $\mathrm{V}_{\mathrm{DS}}$ range, which can hamper the large gate voltage variations under class $A$ amplification.

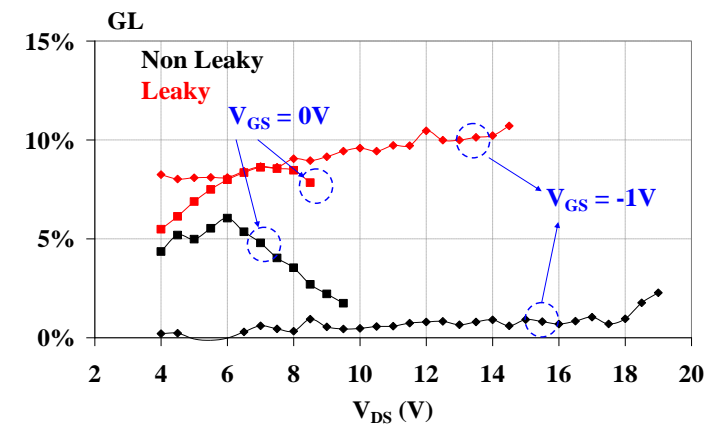

Fig.2. Relative gate lag (GL) between quiescent points @ $\mathrm{V}_{\mathrm{GS} 0}=0 \mathrm{~V} \& \mathrm{~V}_{\mathrm{GS} 0}=-3 \mathrm{~V}$ versus $\mathrm{V}_{\mathrm{DS}}$ (data extracted from measurements shown in Figure 1), for leaky and non-leaky devices.

\subsection{Drain-lag effects}

The drain-lag (DL) is a delayed response of the drain current with respect to the drain voltage variation.

Figure 3 shows 300 ns pulsed I-V measurements of a non-leaky and a leaky HEMTs (Figure 3a for T1 and Figure $3 \mathrm{~b}$ for T2) using the two quiescent bias conditions (2) and (3). T1 and T2 present approximately the same decreasing evolution of the drain lag ratio over the $\mathrm{V}_{\mathrm{DS}}$ measurements range, with less than $10 \%$ of variation between the two extreme biasing conditions $\left(\mathrm{V}_{\mathrm{DS}}=0 \mathrm{~V}, \mathrm{~V}_{\mathrm{DS}}=20 \mathrm{~V}\right)$ over the investigated $V_{D S}$ values. Moreover, the magnitude of the drain-lag is approximately identical for the leaky and non-leaky devices as it differs from less that $3 \%$ over the $\mathrm{V}_{\mathrm{DS}}$ and $\mathrm{V}_{\mathrm{GS}}$ investigated range.

\subsection{Discussion}

The pulsed I-V characteristics of T1 show lower drain current dispersion between $\left(\mathrm{V}_{\mathrm{GS} 0}, \mathrm{~V}_{\mathrm{DS} 0}\right)=(0 \mathrm{~V}, 0 \mathrm{~V})$ and $\left(\mathrm{V}_{\mathrm{GS} 0}, \mathrm{~V}_{\mathrm{DS} 0}\right)=(-3 \mathrm{~V}, 0 \mathrm{~V})$ than T2. This higher gate-lag effect for the leaky device is attributed to traps with time constants higher than 300ns (that is the pulse width) and lower than the period duration (@30 $@$ s).

The pulsed I-V characteristics of $\mathrm{T} 1$ and $\mathrm{T} 2$ between $\left(\mathrm{V}_{\mathrm{GS} 0}, \mathrm{~V}_{\mathrm{DS} 0}\right)$ of $(-3 \mathrm{~V}, 0 \mathrm{~V})$ and $(-3 \mathrm{~V}, 20 \mathrm{~V})$ show almost the same drain lag magnitude. 


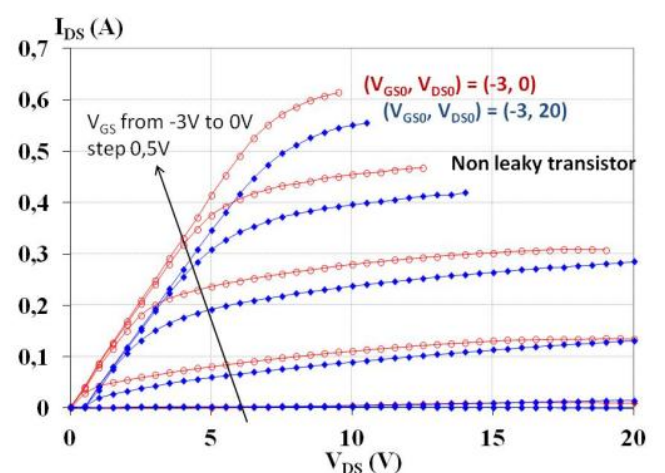

(a)

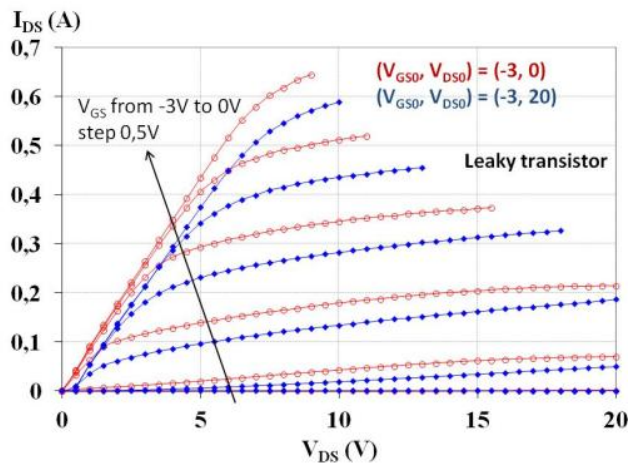

(b)

Fig.3. 300ns pulsed I-V measurements of the AlGaN/GaN HEMTs at QB conditions (2) and (3).

(a) non-leaky transistor $\mathrm{T} 1$.

(b) leaky transistor $\mathrm{T} 2$.

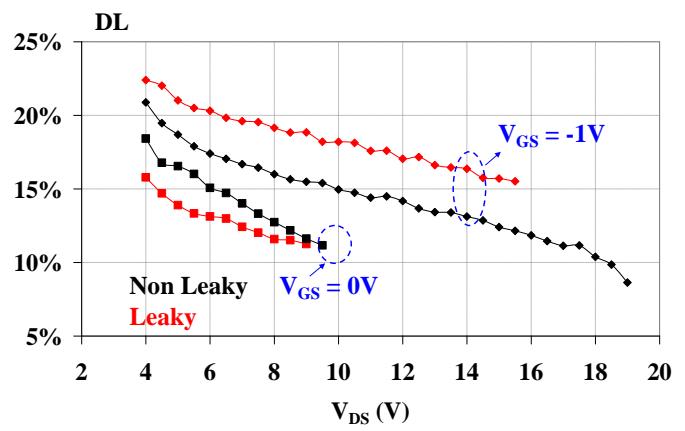

Fig.4. Relative drain lag (DL) between quiescent points @ $\mathrm{V}_{\mathrm{DS} 0}=0 \mathrm{~V} \& \mathrm{~V}_{\mathrm{DS} 0}=20 \mathrm{~V}$ versus $\mathrm{V}_{\mathrm{DS}}$ (data extracted from measurements shown in Figure 3), for leaky and non-leaky devices (for $\mathrm{V}_{\mathrm{GS}}=0 \mathrm{~V}$ and $\mathrm{V}_{\mathrm{GS}}=-1 \mathrm{~V}$ ).

Moreover, the comparison at all quiescent bias conditions between the two transistors shows that the pulsed drain current is always slightly higher for T2 than for T1. This means higher output power for the leaky transistor. From the analysis between the transconductance gains, no difference is noticeable from DC measurements over a wide temperature range $(100 \mathrm{~K}-400 \mathrm{~K})$ for the leaky and non-leaky devices. However, transconductance gain $\mathrm{g}_{\mathrm{m}}$ from pulsed measurements at ambient temperature features large difference versus gate voltage $\left(\mathrm{g}_{\mathrm{m}-\mathrm{max}}, \mathrm{V}_{\mathrm{th}}\right)$ (figure 5). As the dynamic transconductance gain is not higher for the leaky device, and considering identical piezoelectric and spontaneous charges for the leaky and non-leaky devices (same structures), this increase in the current for the leaky transistor T2 can be attributed to a higher density of charges $n_{i}$. This manifestation on pulsed measurements $\left(\mathrm{I}_{\mathrm{DS}}-\mathrm{V}_{\mathrm{DS}}, \mathrm{g}_{\mathrm{m}}\right)$ can be explained through the compensation of donors by dynamic charges (dynamic change of the space charge region depth in the 2DEG).

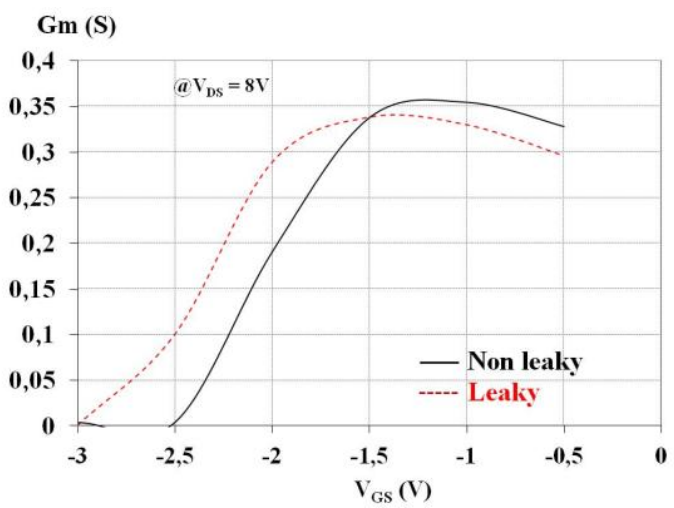

Fig.5. pulsed transconductance gain versus $\mathrm{V}_{\mathrm{GS}}$ for leaky and non-leaky devices $@ \mathrm{~V}_{\mathrm{DS}}=8 \mathrm{~V}$.

Moreover, a shift between the ohmic curves at $\mathrm{V}_{\mathrm{DS}}=0 \mathrm{~V}$ and $\mathrm{V}_{\mathrm{DS}}=20 \mathrm{~V}$ (Figure $3 \mathrm{a}$ and $3 \mathrm{~b}$ ) can be observed. This shift has been found to be reproducible and depends on the pulse width and on the $\mathrm{V}_{\mathrm{DS} 0}$ quiescent voltage. This can be modeled by an intrinsic voltage generator between drain and source that increases by $-0.5 \mathrm{~V}$ when $\mathrm{V}_{\mathrm{DS} 0}$ varies from $0 \mathrm{~V}$ to $20 \mathrm{~V}$ for both leaky and non leaky devices. The origin of this $\mathrm{V}_{\mathrm{DS} 0}$-activated mechanism is not yet identified.

From Figure 4 on the relative drain lag values (expressed in \%), two different trends can be sorted out at $\mathrm{V}_{\mathrm{GS}}=0 \mathrm{~V}$ and at $\mathrm{V}_{\mathrm{GS}}=-1 \mathrm{~V}$ :

(a) At $\mathrm{V}_{\mathrm{GS}}=0 \mathrm{~V}$, more pronounced lag effects are visible in the ohmic region (low $\mathrm{V}_{\mathrm{DS}}$ values), whereas the difference decreases when $V_{D S}$ measurement increases. An identical relative drain lag is obtained (11\%) for leaky and non-leaky devices at a measurement condition of $\mathrm{V}_{\mathrm{DS}}=10 \mathrm{~V}$. This former condition concerns a situation when the relative voltage variation from quiescent to measurement $\left(\left|\mathrm{V}_{\mathrm{DS} 0}-\mathrm{V}_{\mathrm{DS}}\right|\right)$ is the same (i.e. same difference between the quiescent condition, $\mathrm{V}_{\mathrm{DS} 0}=0 \mathrm{~V}$ and $\mathrm{V}_{\mathrm{DS} 0}=20 \mathrm{~V}$, and the measurement point at $\left.\mathrm{V}_{\mathrm{DS}}=10 \mathrm{~V}\right)$. Here are under concern traps between gate and drain, probably located at the AlGaN/GaN interface. More information can be found in [4], where gate lag effects are discussed (i.e. same mechanisms between G-S region). 
(b) At $\mathrm{V}_{\mathrm{GS}}=-1 \mathrm{~V}$, the leaky and non-leaky devices feature the same behavior (same slope of the relative drain-lag regression versus $\mathrm{V}_{\mathrm{DS}}$ ). Thus it can be assumed that another mechanism is superimposed to the previous one. Here, the same mechanism is involved for both the leaky and nonleaky devices under the gate biasing conditions $\mathrm{V}_{\mathrm{GS}}=0 \mathrm{~V}$, even if the lag effect is more pronounced for the leaky device (more traps activated).

\section{Gate and drain low frequency noise measurements}

\subsection{Gate current noise spectral density}

The LFN measurements on gate and drain terminals are performed at room temperature. Figure 6 shows the gate current noise spectral density $\left(\mathrm{S}_{\mathrm{IG}}\right)$ of non-leaky (T1) and leaky (T2) transistors at $\mathrm{V}_{\mathrm{GS}}=-3 \mathrm{~V}, \mathrm{~V}_{\mathrm{DS}}=8 \mathrm{~V}$ and $\mathrm{V}_{\mathrm{GS}}=-5 \mathrm{~V}, \mathrm{~V}_{\mathrm{DS}}=8 \mathrm{~V}$. A difference in the noise level is noticed as T2 presents a noise level 3 decades higher than the spectra related to T1. Moreover, the spectra shape (i.e. noise sources contributing to the overall noise) differs for the two devices, revealing different conduction mechanisms for $\mathrm{T} 1$ and $\mathrm{T} 2$. While the $1 / \mathrm{f}$ noise source of the non leaky device is only masked at high frequencies (frequency $>1 \mathrm{kHz}$ ), the $1 / \mathrm{f}$ noise source cannot be extracted from the spectra for the leaky device: a large number of traps (GR centers) are revealed by the $S_{\text {IG }}$ spectra of $\mathrm{T} 2$. Thus, the power current law $\mathrm{S}_{\mathrm{IG}_{\mathrm{G}}} \sim \mathrm{I}_{\mathrm{G}}{ }^{\mathrm{x}}$ does not evolve with the same $\mathrm{x}$ index for the leaky and non leaky devices [9].

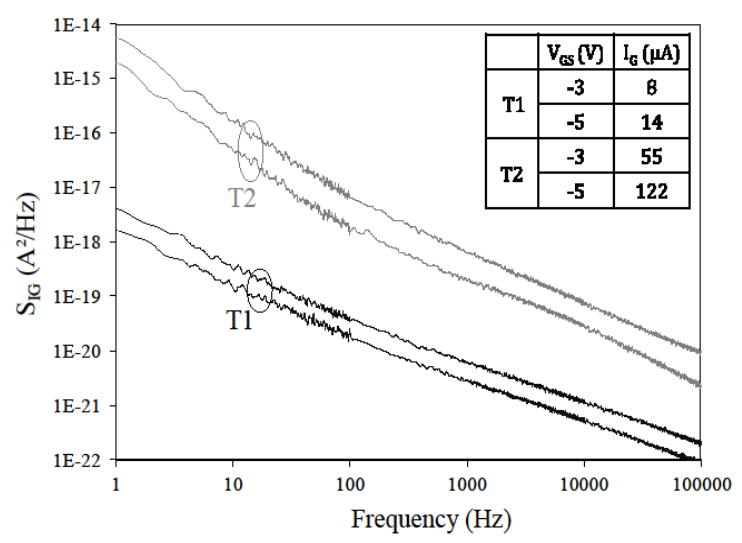

Fig. 6. Gate noise current spectral density of the AlGaN/GaN HEMTs (T1: non-leaky transistor and

$\mathrm{T} 2$ : leaky transistor) biased at $\mathrm{V}_{\mathrm{GS}}=-3 \mathrm{~V}$ and $-5 \mathrm{~V}$.

\subsection{Drain current noise spectral density}

Another aspect concerning the defects in the device is the study of the LFN on the drain access. Figure 7 presents the low frequency noise measurements performed on the drain current $\left(\mathrm{S}_{\mathrm{ID}}\right)$ for $\mathrm{T} 1$ and $\mathrm{T} 2$.
Both transistors feature the same $\mathrm{S}_{\mathrm{ID}}$ level (for the same $\mathrm{I}_{\mathrm{DS}}$ current): the two spectra of $\mathrm{T} 1$ and $\mathrm{T} 2$ are quasisuperimposed, in spite of a difference of less than one decade at low frequencies between $10 \mathrm{~Hz}$ and $100 \mathrm{~Hz}$ due to more pronounced GR centers effect for the leaky device [9]. These GR centers (time constants between $0.01 \mathrm{~s}$ and more than $1 \mathrm{~s}$ ) measured under isothermal conditions can be related to the defects discussed in section 3.3 .

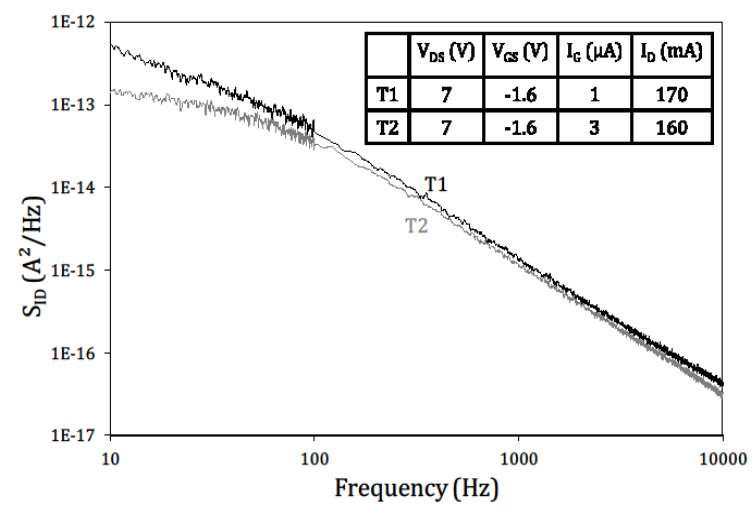

Fig. 7. Drain noise current spectral density of the AlGaN/GaN HEMTs (T1: non-leaky transistor and T2: leaky transistor) biased at $\mathrm{V}_{\mathrm{GS}}=-1.6 \mathrm{~V}$ and $\mathrm{V}_{\mathrm{DS}}=7 \mathrm{~V}$.

Figure 8 reports on the drain LFN measurements of three samples from the same set of devices (referred as $\mathrm{T} 1$ in this paper: non-leaky devices). The obtained results can be considered as statistically relevant. Moreover, the LFN drain current noise spectra are known to be an accurate prober of the crystal defects in the transistor: the absence of dispersion stands as a good indicator of the homogeneity of the devices under test. As shown in Figures 8 and 9, thermally activated defects are evidenced for three different biasing conditions (temperature increases when $\mathrm{P}_{\mathrm{DC}}=\mathrm{I}_{\mathrm{DS}} \cdot \mathrm{V}_{\mathrm{DS}}$ increases, at constant $\mathrm{V}_{\mathrm{DS}}$ when $\mathrm{I}_{\mathrm{DS}}$ varies with $\mathrm{V}_{\mathrm{GS}}$ ).

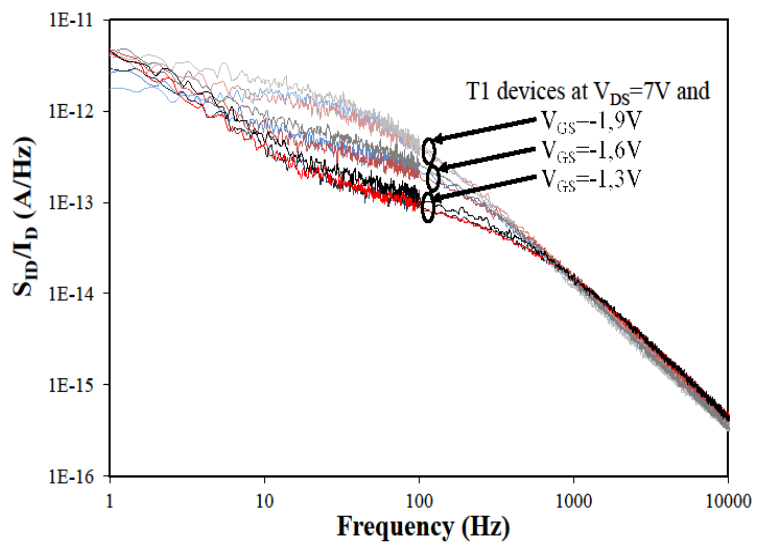

Fig. 8. Drain noise current spectral densities normalized versus drain current for three T1-type devices. The measurements are performed at constant $\mathrm{V}_{\mathrm{DS}}$ value of $7 \mathrm{~V}$ and at $\mathrm{V}_{\mathrm{GS}}=-1.9$ to $-1.3 \mathrm{~V}$ with $\Delta \mathrm{V}_{\mathrm{GS}}=0.3 \mathrm{~V}$. 


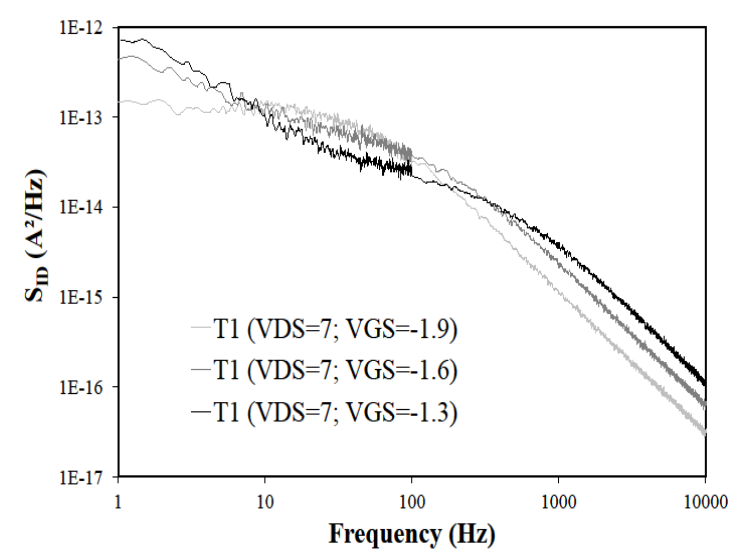

Fig. 9. Drain noise current spectral densities of $\mathrm{T} 1$ at $\mathrm{V}_{\mathrm{DS}}=7 \mathrm{~V}$ and at $\mathrm{V}_{\mathrm{GS}}=-1.9$ to $-1.3 \mathrm{~V}$ with $\Delta \mathrm{V}_{\mathrm{GS}}=0.3 \mathrm{~V}$.

\subsection{Discussion}

The insets in Figures 6 and 7 indicate the difference between the gate currents of the devices under test $\left(14 \mu \mathrm{A}\right.$ for $\mathrm{T} 1$ and $122 \mu \mathrm{A}$ for $\mathrm{T} 2$ at $\mathrm{V}_{\mathrm{GS}}=-5 \mathrm{~V}$ and $\mathrm{V}_{\mathrm{DS}}=8 \mathrm{~V}$ ), whereas the devices feature quasi-identical drain currents values. According to Vandamme and al. [10-11], devices with slight differences in drain current noise can have quite a different gate current noise. Actually, these results are quite consistent with pulsed electrical characterizations, as the numerous traps revealed by $\mathrm{LFN}$ on the gate terminal can reasonably be correlated with a higher level of gate lag on the leaky devices. These traps act as trapping-detrapping processes with time constants ranging from few microseconds to some seconds (also revealed by pulsed I-V transient characterizations). The surface passivation and the mastering of the gate Schottky diode are key points concerning the performance and the reliability of the devices, through a reduction of traps and leakage currents. Concerning the drain terminal, no strong difference is noticed between leaky and non-leaky sets of devices, in spite of numerous GR centers revealed by LFN characterization in the lower frequency band. Traps have been located at the interface between the $\mathrm{AlGaN}$ and GaN layers, and are activated with the extension of the space charge region between gate-source and gate-drain regions when the respective voltages $V_{G S}$ and $V_{D G}$ are applied [4]. Moreover, no correlation is found between noise current densities of gate and drain terminals.

\section{Conclusion}

The paper presents a synthesis issued from different experimental techniques performed on the gate and drain currents of AlGaN/GaN HEMTs. Pulsed electrical measurements and low frequency noise measurements evidence the importance in mastering the gate Schottky diode, and specially lowering the gate leakage currents, to lower the lag effects and the noise sources (GR centers). The gate-lag effect and GR centers have been associated to the ionized donor states located on the surface [13] as well as to the trapping centers located in the barrier or in the buffer [8]. Despite the importance of the drain access and hence of the drain current, the gate leakage current is a major indicator to follow up; the results indicate that the gate technological process remains a critical issue for the qualification of competitive and reliable $\mathrm{GaN}$ technologies. However, at this stage of the development, the devices feature an elevated median time to failure (MTTF) at $3.10^{7}$ (resp. at $2.10^{6}$ ) hours for a junction temperature of $175^{\circ} \mathrm{C}$ (resp. $\left.200^{\circ} \mathrm{C}\right)$ [13].

\section{Acknowledgements}

The authors would like to thank ANR for the funding $\mathrm{ReAGaN}$ research program.

\section{References}

[1] H. Morkoc, Handbook of Nitride Semiconductors and Devices, Wiley-Vch Verlag GmbH and Co. KGaA.

[2] C. Charbonniaud and al. $11^{\text {th }}$ GAAS Symp. Munich, Germany, Oct. 6-7, 2003, pp. 201-204.

[3] J.M. Tirado, J.L. sanchez-Rojas and J.I. Izpura IEEE Trans. on Elec. Devices, Vol.541, No. 3, pp. 410-417, 2007.

[4] J.G. Tartarin, G.Astre, S. Karboyan, T. Noutsa and B. Lambert, proceedings IWS 2013, April 2013, Beijin, China.

[5] A. Balandin, S. V. Morozov, S. Cai, R. Li, K. L. Wang, G. Wijertane and C.R. Viswanathan, IEEE Trans. on Microwave Theory and Techniques, Vol. 47, No. 8, pp.14131417, 1999.

[6] J. Graffeuil and R. Plana, $24^{\text {th }}$ European Microwave Conference, (1994) pp. 62-75.

[7] L.K.J. Vandamme, IEEE Transaction on Elec. Devices, Vol. 41, No. 11, pp. 2176-2187, 1994.

[8] O. Mitrofanov and M. Manfra, Superlattices and Microstructures 34 (2003) 33-53.

[9] S. Karboyan, J.G. Tartarin, N. Labat and B. Lambert, $22^{\text {th }}$ International Conference on Noise and Fluctuations, 2013.

[10] L.K.J. Vandamme, D. Rigaud, and J.M. Peransin, IEEE Trans. on Elec. Devices, Vol.39, No.10, pp.2377-2382, 1992.

[11] L.K.J. Vandamme, D. Rigaud, J.M. Peransin, R. Alabedra and J.M. Dumas, IEEE Trans. on Electron Devices, Vol. 35, pp. 1071-1075, 1988.

[12] R. Vetury, Q. Zhang, S. Keller and U.K. Mishra, IEEE Trans. on Electron Devices 48 (2001) 560.

[13] B. Lambert, J, Thorpe, R. Behtash et al., Microelec. Reliability, 52 (9-10), pp. 2200-2204 (2012). 